\title{
A minireview on NHE1 inhibitors. A rediscovered hope in oncohematology
}

\author{
Romeo Gabriel Mihaila
}

\begin{abstract}
Background. $\mathrm{Na}^{+} / \mathrm{H}^{+}$exchanger-1 (NHE-1) is involved in $\mathrm{pH}$ regulation and is up-regulated in different malignancies. Activation of NHE-1 is one way for allowing cells to avoid intracellular acidification and protect them against apoptosis. Inhibitors of NHE-1 are able to decrease intracellular $\mathrm{pH}$ and induce apoptosis. Some statins can also act by partial inhibition of NHE-1. This review presents progress in understanding the mechanisms of action of these inhibitors, connections with certain genetic mutations and acquired treatment resistance, as well as new patents on them.

Methods. A MEDLINE search for original and review articles using key terms, $\mathrm{Na}^{+} / \mathrm{H}^{+}$exchanger, leukemia, cariporide, and amiloride. Recent patents with NHE-1 inhibitors published by United States Patent and Trademark Office are also presented.

Results and Conclusions. Sorafenib is used for the treatment of acute myeloid leukemia patients carrying internal tandem duplication of fms-like tyrosine kinase 3 (FLT3-ITD) mutation. 5-(N, N-hexamethylene)-amiloride can increase the suppression of FLT3 signaling by sorafenib. NHE-1 inhibitors are able to increase the sensitivity of chronic myeloid leukemia cells to tyrosine kinase inhibitors, including through the inhibition of P-glycoprotein. NHE-1 inhibitors are promising adjuvant drugs for overcoming acquired resistance to treatment in various malignant hemopathies.
\end{abstract}

Key words: amiloride, apoptosis, $B C R / A B L$, cariporide, FLT3/ITD, heme oxygenase-1, leukemia, $\mathrm{Na}^{+} / \mathrm{H}^{+}$exchanger, imatinib mesylate, intracellular $\mathrm{pH}$, isoprenylation, leukemia, lovastatin, P-glycoprotein, sorafenib, statins

Received: September 13, 2015; Accepted with revision: November 23, 2015; Available online: November 27, 2015 http://dx.doi.org/10.5507/bp.2015.060

Faculty of Medicine, "Lucian Blaga" University of Sibiu and Department of Hematology, Emergency County Clinical Hospital Sibiu, Romania Corresponding author: Romeo Gabriel Mihaila, e-mail: romeomihaila@yahoo.com

\section{INTRODUCTION}

\section{Intra- and extracellular $\mathrm{pH}$}

The microenvironment in which the tumor cells grow is more acidic compared to that of the surrounding normal cells ${ }^{1}$. Responsible for the aberrant $\mathrm{pH}$ gradient present in most types of cancers are some proton exchangers and transporters, including $\mathrm{Na}^{+} / \mathrm{H}^{+}$exchanger (NHE), proton pump vacuolar-type ATPase, carbonic anhydrases, monocarboxylate transporters ${ }^{2}, \mathrm{Na}^{(+)} / \mathrm{HCO}_{3}{ }^{(-)}$ co-transporter, $\mathrm{Cl}^{(-)} / \mathrm{HCO}^{(-)}$exchanger, and adenosinetriphosphate synthase ${ }^{3}$. The consequences of this acidic tumoral microenvironment are the protection of malignant tissue against the body reaction towards cancer growth and the fact that most drugs are protonated, so that they do not enter into cancer cells ${ }^{2}$. Thus, due to its possibility to survive, the cancer cell was compared with unicellular microorganisms rather than with a cell belonging to an organ, compartment or body. It is known that after variable response to chemotherapy, many malignant cells develop clones and subclones resistant to treatment and with more malignant behavior, an explanation for accelerated tumor growth ${ }^{2}$. Multi-drug resistance is associated with acidification of the extracellular environment and alkalinisation of the cytosol, expression of reversal of the $\mathrm{pH}$ gradient during plasma membrane of the malignant cells ${ }^{3}$.

\section{The $\mathrm{Na}^{+} / \mathrm{H}^{+}$exchangers}

Ten NHE isoforms are known and are involved in the removal of one intracellular proton in exchange for one extracellular sodium. This exchanger is regulated at posttranslational level and by different regulatory-binding proteins. Besides the regulation of intracellular $\mathrm{pH}$, it is involved in various normal and pathological cellular processes, including cell-cycle regulation, apoptosis ${ }^{4}$, cell movement, those present in heart disease ${ }^{5}$ and cancer ${ }^{4,5}$. $\mathrm{Na}^{+} / \mathrm{H}^{+}$exchanger-1 (NHE-1), present in mammalian cells plasma membrane ${ }^{5}$, is a growth factor-activatable exchanger ${ }^{4}$ and it is the best characterized one ${ }^{5}$.

NHE-1 is an integral membrane transport protein ${ }^{6}$ and one of the most important systems involved in $\mathrm{pH}$ regulation, so that tumor cells can withstand in acid microenvironment ${ }^{1}$. It is an important contributor to the production and maintaining a reversed proton gradient in malignant cells $^{6,7}$. Its activity is important in particular at the beginning of cell division and during cell proliferation ${ }^{1,8}$. It was shown that NHE-1 becomes activated during malignant cell transformation and is further activated by different hormones, growth factors, metabolic microenvironment or by ECM receptor activation ${ }^{6}$. Increased activity of NHE-1 can be correlated with both a rise of intracellular $\mathrm{pH}$ and a reduction of extracellular $\mathrm{pH}$ of tumor tissue. The activation of NHE-1 and of other proton pumps and transporters allow cells to avoid intracellular acidification, which could lead to their apoptosis ${ }^{7}$. The long term administration of ion pump inhibitors, which is a selective target of anticancer therapy ${ }^{7}$, studied in vitro, showed that it is able to suppress tumor growth ${ }^{1}$.

It is well-known that leukemic cell lines have higher intracellular $\mathrm{pH}$ than normal hematopoietic cells. In ad- 
dition, it has been demonstrated that the administration of 5-(N, N-hexamethylene)-amiloride (HMA) is able to decrease intracellular $\mathrm{pH}$ and induce apoptosis: after incubation of patient leukemic cells with this drug for five hours, while intracellular $\mathrm{pH}$ decreased, a rate of over $90 \%$ of leukemic cells were killed ${ }^{4}$. This exchanger inhibitor can also potentiate the cytotoxic and phototoxic effect of hypericin on HL60 cell line and, respectively, on human leukemia CEM cell line 9 $^{90}$. Cariporide is a specific and powerful NHE-1 inhibitor, well studied, relatively well tolerated by humans in terms of cardiology but slightly toxic due to its accumulation and cerebrovascular complications. Cariporide is considered to be an effective anticancer drug ${ }^{7}$. Other NHE-1 inhibitors of the non-amiloride series such as Phx-3 and Compound 9t, that are effective anticancer agents, with minimal toxicity ${ }^{7}$, require extensive studies on their usefulness in various types of solid and hematological malignancies.

The attention given to NHE-1 inhibitors has recently increased due to the discovery that one drug used for the treatment of resistant forms of acute myeloid leukemia with a known genetic mutation can induce NHE-1 overexpression $^{11}$, and that in chronic myeloid leukemia resistant to imatinib the inhibition of this exchanger can reverse the resistance to this thyrosine kinase inhibitor ${ }^{12}$. Thus, the study of NHE-1 inhibitors has become a topical issue. There is hope for overcoming multidrug resistance and to achieve a more efficient treatment of hematological malignancies. We conducted a rewiev of articles published in PubMed, selected using the terms: "leukemia" and " $\mathrm{Na}^{+} /$ $\mathrm{H}^{+}$exchanger", "cariporide" or "amiloride". Recent patents with HNE-1 inhibitors published by United States Patent and Trademark Office are also presented.

\section{PATHOPHYSIOLOGICAL ASPECTS}

\section{New data on NHE-1 function}

NHE-1 is an ATP-dependent pump which is involved in some fundamental cellular processes. Its overexpression has a role in cellular alkalinization and its inhibition in cellular acidification. An acidification by $0.5-0.6 \mathrm{pH}$ units obtained with $\mathrm{N}$-methyl-N'-nitro-N-nitrosoguanidine usually induces cell apoptosis while permitting necrotic death of cells with wide DNA lesions ${ }^{13}$. The decreased activity of NHE-1 mediates differentiation of K562 cells by way of extracellular signal-regulated protein kinases $1 / 2$ (ERK1/2) mechanism, targeted by cytokine-induced antiapoptotic inhibitor 1, a downstream effector of the Ras signaling mechanism ${ }^{14}$. ERK1/2 are intracellular signaling molecules of type protein kinase, component of Ras-RafMEK-ERK signaling cascade, involved in cell proliferation and apoptosis. Their cytosolic retention prevents the mitogenic response by impeding the transcriptional factor access to its substrate, and here they increase the catalytic activity of some proteins with proapoptotic function ${ }^{15}$. ERK2 signaling is required for Ras induced epithelial-tomesenchymal transformation ${ }^{16}$.
A silent polymorphism of nucleotides 112,2248 , and 2493 within the coding region of human NHE-1 cDNA was seen both in normal peripheral blood mononuclear cells and leukemic cells, so that this polymorphism is not involved in the pathogenesis of leukemia as a notable event $^{17}$.

\section{The osmolarity and the activity of NHE}

The osmolarity of the extracellular environment may influence the activity of NHE. Thus, while NHE of human promyelocytic leukemic HL-60 cells was largely dormant during resting isotonic media, it was significantly activated when the cells were introduced in a hypotonic environment, after $30 \mathrm{~min}$ of regulatory volume decrease, although $\mathrm{pHi}$ and cell volume returned to near-normal levels. The activity of NHE may undergo a shift depending on $\mathrm{pHi}$ and/or cell volume during regulatory volume decrease in hypotonic media ${ }^{18}$.

\section{Hypoxia and NHE-1 inhibition}

It was observed that hypoxia can induce differentiation of K562 cells by NHE-1 inhibition, process which may be due to up-regulation of CCAAT/enhancer-binding protein $\alpha$ via $\mathrm{p} 38$-mitogen-activated protein kinase (p38 MAPK) signaling mechanism ${ }^{19,20}$. The fact that cariporide synergistically enhanced K562 cells differentiation in hypoxic microenvironment (obtained with a mimetic agent $\mathrm{CoCl}_{2}$ or under hypoxic condition of culture) was also communicated in another article, in which increased levels of phosphorylated ERK 5 by cariporide treatment were shown ${ }^{20}$.

\section{DNA damage and intracellular alkalinisation}

It was shown that DNA damage in thymocytes produced up-regulation of the NHE-1 antiport, followed by intracellular alkalinisation, Bcl-xL deamidation, and apoptosis $^{21}$. In tumor cells expressing an oncogenic tyrosine kinase this pathogenetic chain induced by DNA damage is blocked. The implementation of intracellular alkalinisation resulted in effects that mimic those induced by DNA damage in human B-lineage chronic lymphocytic leukemia cells and murine tumor cells involved in Bcl$\mathrm{xL}$ deamidation and apoptosis increase. The increased expression of the NHE-1 antiport is considered to be an event both necessary and sufficient for further intracellular alkalinisation, followed by Bcl-xL deamidation, and then by apoptosis ${ }^{21}$. Instead, DNA damage was not followed by the activation of this pathogenetic chain in patients with polycythemia vera or chronic myeloid leukemia, as the $\mathrm{Bcl}-\mathrm{x}(\mathrm{L})$ deamidation pathway is inhibited in CD34+ progenitor cells and mature myeloid cells (but not in T cells) carrying the mutation $J A K 2 V 617 F$ or $B C R-A B L$. JAK2 inhibitors and imatinib could reverse the inhibition of this pathogenetic chain, but not in the cells bearing a mutation in the $B C R-A B L$ kinase domain which confers resistance to imatinib ${ }^{22}$. 


\section{PROGRESS ON KNOWLEDGE REGARDING THE MECHANISMS OF ACTION OF NHE-1 INHIBITORS}

\section{Amiloride}

It has been observed for a long time that leukemia cells in vivo or in vitro have a significantly higher intracellular $\mathrm{pH}$ compared to normal hematopoietic cells. NHE-1 is the main regulator of intracellular $\mathrm{pH}^{23}$. But amiloride, the first drug described as inhibitor of NHE-1 (ref. ${ }^{24}$ ), can modulate the alternative splicing of a wide range of genes involved in cancer pathogenesis, such as $B C R / A B L, B c l-x$, and $H I P K 3$, and this result is not mainly related to $\mathrm{pH}$ modification ${ }^{25}$. Amiloride is also involved in regulation of various apoptotic genes, including SURVIVIN, APAF-1, and CRK, as it was shown by genome-wide detection of alternative splicing. It was found that different proteins of the MAPK kinases and Bcl-2 family are implicated in amiloride-induced apoptosis. These data emphasize the complexity of the mechanisms of action of amiloride and the fact that it is a promising drug for the treatment of malignant hemopathies. So far as we know the combined treatment of amiloride and imatinib applied to K562 and BaF3/Bcr-AblT315I cells leads to a greater loss of cell viability compared to each drug separately ${ }^{25}$.

\section{5'-(N,N-dimethyl)-amiloride and 5-(N, N-hexamethylene)- amiloride}

A double substitution of the nitrogen of the 5-amino group of amiloride allowed to obtain $5^{-}-(\mathrm{N}, \mathrm{N}$-dimethyl)amiloride (DMA), 5-N-ethyl-N-isopropyl amiloride (EIPA) and HMA (ref. ${ }^{24}$ ). DMA can significantly potentate the activity of hypericin in leukemic CEM cell line, contributing to the production of excited-state proton transfer and consequent cytoplasmic cell acidification induced by hypericin ${ }^{9}$. When pharmacologic doses of HMA were added to in vitro incubated leukemic cells, after $5 \mathrm{~h}$, their intracellular $\mathrm{pH}$ decreased and apoptosis increased so that more than $90 \%$ of the leukemic cells were killed. Normal and leukemic cells have a different sensitivity to NHE-1 inhibitors, so that these drugs could be antileukemic agents ${ }^{23}$.

\section{Cariporide}

The simultaneous substitution of the pyrazine ring by a phenyl, of the 6-chloro by a sulfomethyl led to drugs such as HOE-694, cariporide, eniporide and BIIB-513, which are selective inhibitors of NHE-1 (ref. ${ }^{24}$ ). Cariporide was used in various experiments with promising results.

Thus, the decrease in intracellular $\mathrm{pH}$ in human umbilical cord-derived mesenchymal stem cells using cariporide was followed by their up-regulated osteogenic differentiation, whereas the adipogenic differentiation was not influenced. An up-regulated expression of $\beta$-catenin was required for this osteogenic differentiation ${ }^{26}$.

How to increase apoptosis of leukemia cells? The inhibition of NHE-1 by cariporide produced an endoplasmic reticulum stress-induced up-regulation of the death receptor 5 , which is mediated at transcriptional level by CCAAT/enhancer binding protein homologous protein
(CHOP). It was shown that endoplasmic reticulum stress triggered the death of tumor cell through CHOP. The use of cariporide in association with tumor necrosis factor related apoptosis-inducing ligand allowed to obtain a greater degree of apoptosis. The use of a combination between cariporide and death receptor 5 agonists could be a way to obtain apoptosis in leukemic cells ${ }^{27}$.

There is also a connection between intracellular $\mathrm{pH}$ and microvessel density. A decrease in intracellular $\mathrm{pH}$ and a down-regulation of VEGF secretion were observed when cariporide was administered to K562 leukemic cells. The drug administered subcutaneously in nude mice produced an inhibition of K562 tumor cells growth and a reduction of microvessels density ${ }^{28}$.

\section{THE INTERACTION BETWEEN STATINS AND NHE}

It was shown that some statins are involved in intracellular acidification. Thus, lovastatin decreases not only cholesterol synthesis, but also protein isoprenylation - a posttranslational modification without which the activity of G-proteins is disrupted. Inhibition of isoprenylation induced by lovastatin is responsible for the occurrence of apoptosis in HL-60 cells associated with dose-dependent intracellular acidification and DNA degradation. This acidification is due to a partial inhibition of NHE. Phorbol myristate acetate could activate protein kinase C and this enzyme was able to suppress lovastatin-induced apoptosis and DNA degradation ${ }^{29}$. EIPA, a NHE inhibitor, demonstrated that it is able to inhibit the effect of phorbol myristate acetate and to induce DNA degradation in HL-60 cells ${ }^{29}$.

It was shown that perillyl alcohol can selectively produce $\mathrm{G} 0 / \mathrm{G} 1$ arrest and then apoptosis in $B C R / A B L$ transformed cells. The inhibitors of protein kinase $\mathrm{C}$ (PKC) and the NHE can block the protective effect of phorbol ester against the cytotoxicity induced by perillyl alcohol. In these cells, perillyl alcohol and lovastatin act by different mechanisms to produce growth arrest: lovastatin inhibits the initial step and perillyl alcohol - a distal one involved in the mevalonate biosynthesis pathway ${ }^{30}$.

\section{FLT3 INHIBITORS AND NHE-1 ACTIVATION}

The treatment of acute myeloid leukemia patients carrying internal tandem duplication of fms-like tyrosine kinase 3 (FLT3-ITD) mutation is a big challenge for hematologists. Unfortunately, this mutation is present in about $30 \%$ of acute myeloid leukemia patients giving them a poor prognosis. FLT3 inhibitors (as sorafenib) are active in cells bearing this mutation, but leukemia progression invariably occurs ${ }^{11,31}$. The mechanisms of this resistance are under investigation. Fig. 1 shows the currently known resistance mechanisms. Recently it was observed that a secondary tyrosine kinase domain mutation can appear after the use of FLT3 inhibitors in these patients, associated with resistance and a poor prognosis ${ }^{31}$. Another 


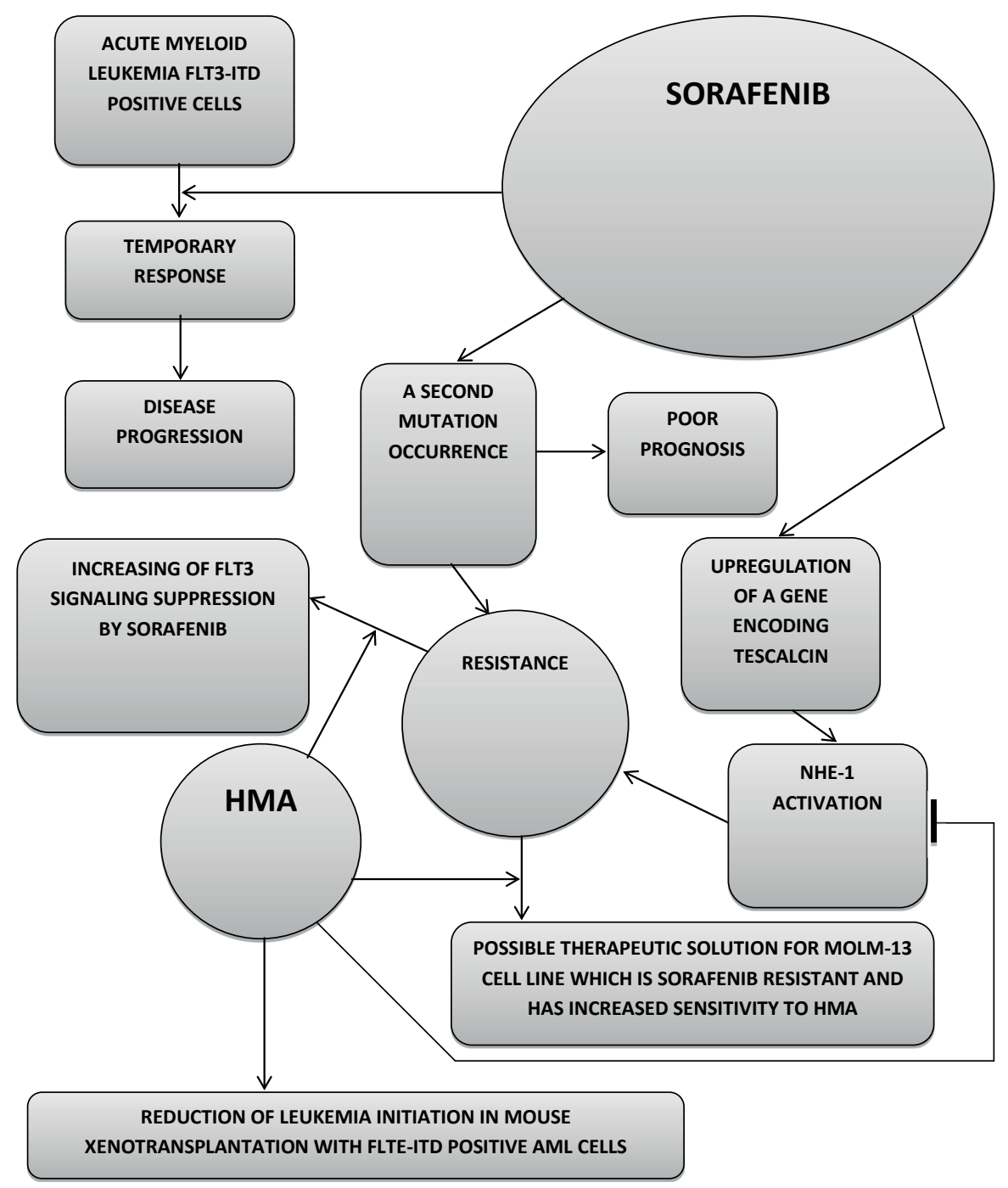

Fig. 1. The mechanisms of resistance to sorafenib.

FLT3-ITD $=$ fms-like tyrosine kinase 3; HMA $=5-(\mathrm{N}, \mathrm{N}$-hexamethylene $)$-amiloride; NHE-1 $=\mathrm{Na}^{+} / \mathrm{H}^{+}$exchanger- 1 .

mechanism involved in this resistance to tyrosine kinase inhibitors is related to a gene encoding tescalcin (TESC), which is upregulated during continuous sorafenib treatment. This gene activates NHE-1 which can underlie the drug resistance. It was shown that the knockdown by small-interfering RNA of $\operatorname{FLT3-ITD(+)}$ acute myeloid leukemia lines MOLM-13 and MV4-11 was able to reduce intracellular $\mathrm{pH}$ and induce apoptosis. The cells with sorafenib resistance, as MOLM-13 cell line, have an increased sensitivity to HMA. This drug can increase the suppression of FLT3 signaling by sorafenib in resistant cells and contribute to reduce leukemia initiation in antiCD122-primed NOD/SCID mouse xenotransplantation with primary $F L T 3-I T D(+)$ acute myeloid leukemia cells treated with it $^{11}$.

\section{NHE-1 IN CHRONIC MYELOID LEUKEMIA}

NHE-1 can induce heme oxygenase-1, an enzyme with antiapoptotic function in K562R cell line and imatinibinsensitive patients with chronic myeloid leukemia. Heme oxygenase-1 is a $B C R / A B L$-dependent survival molecule in this disease, catalyzes the degradation of heme and may be induced by stress. Its levels decreased after treatment with cariporide in K562R cell line and cells from chronic myeloid leukemia patients resistant to imatinib, while intracellular $\mathrm{pH}$ decreased, too ${ }^{32}$. Heme oxygenase- 1 expression, that is induced by NHE-1, can be blocked by the inhibition of $\mathrm{p} 38$ MAPK pathway or by silencing protein kinase $C$ - $\beta$ and NF-E2-related factor 2 (a transcription factor with antioxidant role) (ref. ${ }^{32}$ ). It was shown that p38 MAPK inhibition had a sinergistic effect with cariporide on downregulating the mRNA and protein expression of P-glycoprotein. Even alone, cariporide was able to decrease the protein expression of P-glycoprotein in $\mathrm{K} 562 / \mathrm{G} 01$ and $\mathrm{K} 562 / \mathrm{DOX}$ cells ${ }^{12,33}$, contributed to the 


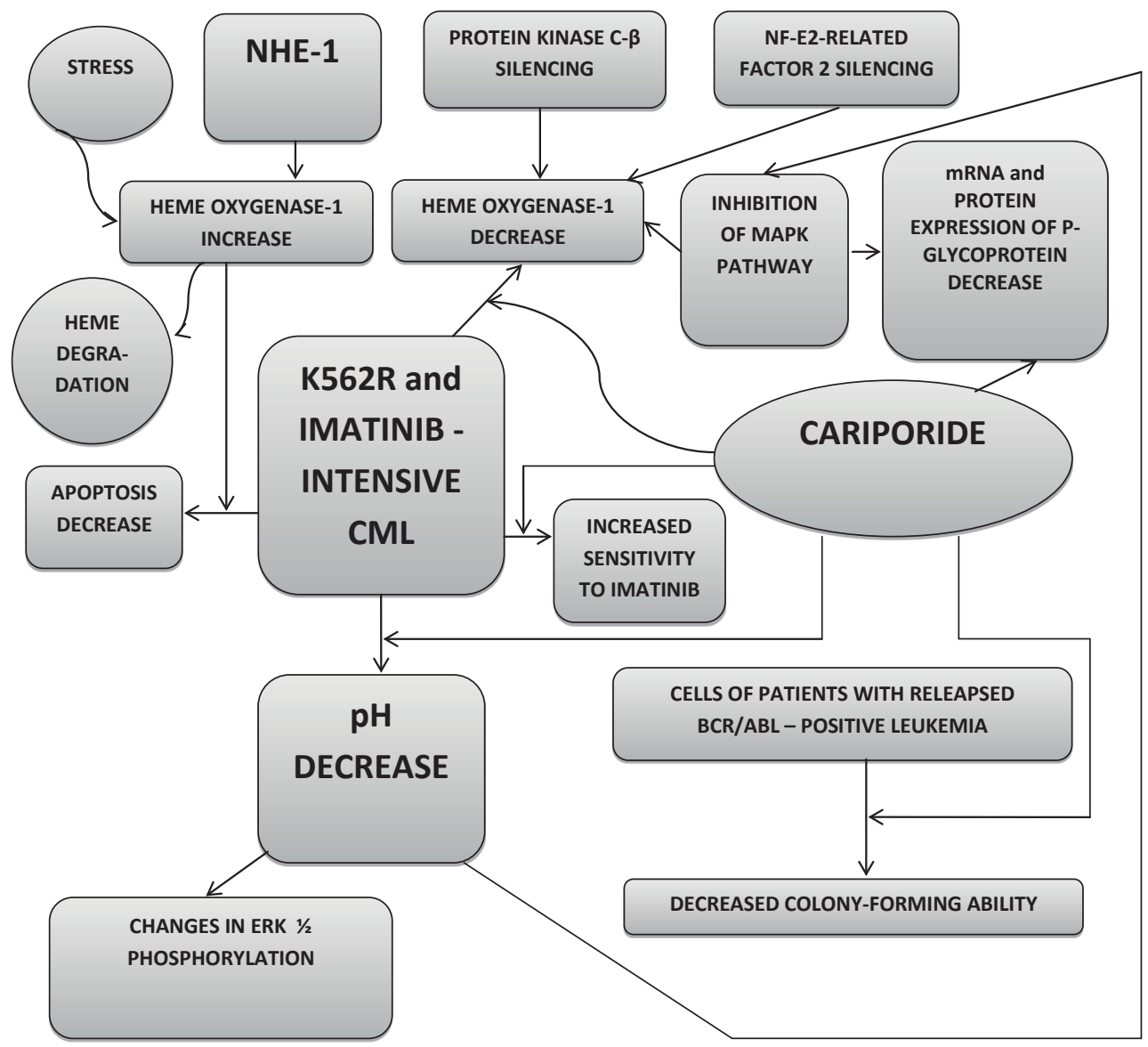

Fig. 2. The interactions in which NHE-1 and cariporide are involved in K562R cell line and imatinib-insensitive cells with chronic myeloid leukemia.

$\mathrm{CML}=$ chronic myeloid leukemia; NHE- $1=\mathrm{Na}^{+} / \mathrm{H}^{+}$exchanger -1 .

accumulation of doxorubicin in the cells of patients with advanced chronic myeloid leukemia, and enhanced the sensitivity of these cells to imatinib ${ }^{33}$. Cariporide also decreased the colony-forming ability of cells from patients with relapsed $B C R-A B L$-positive leukemia ${ }^{12}$. Diminishing the intracellular $\mathrm{pH}$ led to a decrease of $\mathrm{p} 38$ MAPK phosphorylation in cells from patients with advanced chronic myeloid leukemia, and an increase of ERK1/2 phosphorylation within $3 \mathrm{~min}$ and then a decrease of this process after $30 \mathrm{~min}^{33}$. The ability of NHE-1 inhibitors to increase the sensitivity of chronic myeloid leukemia cells to tyrosine kinase inhibitors is a particularly attractive area of research with practical utility. It seems that the inhibition of P-glycoprotein (a drug efflux pump) by NHE-1 inhibitors is also involved in this process ${ }^{12}$. The decrease of intracellular $\mathrm{pH}$ of leukemic cells with high P-glycoprotein expression to 7,0 using the "high $\mathrm{K}^{+"}$ buffer and a specific NHE-1inhibitor produced a decrease of MDR 1 mRNA expression to $16.6+/-7.0 \%$ and of P-glycoprotein expression to $56.0+/-9.0 \%$ after $3 \mathrm{~h}$ of exposure. An increase of intracellular doxorubicin was shown by confocal laser microscopy at the same time ${ }^{34}$. Fig. 2 shows the multiple interactions in which NHE-1 and cariporide are involved in K562R cell line and imatinib-insensitive cells with chronic myeloid leukemia.

\section{RECENT PATENTS WITH NHE-1 INHIBITORS AND STATINS}

Some statins can action by a partial inhibition of NHE, as shown above ${ }^{26}$.

A system that can enhance cell retention of a medicinal agent using a magnetic field was invented ${ }^{35}$. The agent (cells, protein or drug) is marked in advance ex vivo with a force responsive moiety, which can be a complex having a metal, a metal binding protein associated with a metal, or other molecule, that is sensitive and responsive to an internally or externally applied magnetic field. The therapeutic agent can be labeled with human or humanized antibodies directed against different antigens, such as: CD4, CD8, CD34, CD38, c-Kit, stem cell factor, leukocyte common antigen, lineage surface antigen, stem cell antigen. This agent can be employed with amiloride, cariporide, or atorvastatin, pitavastatin, pravastatin, rosuvastatin ${ }^{35}$.

Some tricyclic compounds were invented in order to inhibit the activity of one or more protein kinases with abnormal or deregulated activity, including those of Janus kinase family, fusion kinases, receptor kinase for stem cell factor, and others which are involved in the development of leukemia, lymphoma, myeloma, and other hematopoietic malignancies. These compounds can be combined 
with cariporide or pravastatin sodium, atorvastatin calcium, rosuvastatin for the treatment of myocardial infarction $^{36,37}$, but they can also be used in hematological malignancies.

The new invention is related to composition and methods useful for targeting protein kinases related to MAPK and/or casein kinase pathways, and diseases and disorders related to these kinases. The composition and methods used in this invention are useful in prevention and/or treatment of leukemia, lymphoma, and multiple myeloma, where the mentioned protein kinases are overactivated or over-expressed. The inhibitors of these protein kinases are orally bioavailable and can be used not only in animal experiments, but also in human therapy, alone or in association with other drugs, such as amiloride, cariporide or pravastatin, simvastatin, atorvastatin, fluvastatin, cerivastatin, itavastatin, rosuvastatin, atavastatin, visas$\operatorname{tatin}^{38}$

Multispecific binding proteins obtained by genetic engineering techniques as chemical conjugation, cell fusion, or recombinant DNA, are capable of binding at least two antigens that could be expressed by different types of acute or chronic leukemia or lymphoma cells, which are thus therapeutic targets. Cariporide or some statins (as pravastatin sodium, atorvastatin calcium, or rosuvastatin) can be combined with these binding proteins ${ }^{39}$.

Methods were invented in order to use different compositions to overcome polymorphism, solubility and delivery problems, to control release rates, enhance efficacy, and improve their production and use. The composition contains an ionic liquid at a temperature from about $-30^{\circ}$ $\mathrm{C}$ to about $125^{\circ} \mathrm{C}$, and a herbicidal active cation. Among drugs with ionic structure or drugs that can be combined with ions to form ionic liquids combinations are also included amiloride, cariporide or fluvastatin sodium, lovastatin, pravastatin sodium, simvastatin ${ }^{40}$.

An invention was recently published related to a new technique for purifying antibodies expressed in a host cell expression system that comprises a reduced amount of host cell protein. TNF-alpha antibodies can be used for the treatment of various diseases, including multiple myeloma, due to the fact that in this disease TNF-alpha activity is detrimental. These TNF-alpha antibodies can be given in combination with cariporide or pravastatin sodium, atorvastatin calcium, rosuvastatin, ezetimibe/ simvastatin, avasimibe, indicated in the treatment of myocardial infarction ${ }^{41}$, but also useful in multiple myeloma treatment.

A combination of drugs that act against the expression or activity of CCR2 chemokine receptor, involved in acute lymphoblastic or myeloid leukemia and lymphoma pathway, has recently been reported. These drugs can be combined with cariporide or pravastatin sodium, atorvastatin calcium, rosuvastatin, ezetimibe/simvastatin, avasimibe, for the treatment of myocardial infarction ${ }^{42}$, but the association could also be studied for its efficacy against leukemia or lymphoma.

New systems and methods for the detection of analytes were recently designed. One technique uses a solution with magnetic particles which have bonded moieties on their surface in order to alter their aggregation. The liquid sample with magnetic particles is placed in a device along with multivalent binding agent and the analyte. A radio frequency coil is used to detect the analyte, which is a signal produced by exposing the liquid sample that needs to be analyzed to a bias magnetic field. The invention is designed for the detection of a wide range of analytes used for the diagnosis, management, and/or treatment of bone marrow failure, myelodysplasia, various types of acute or chronic myeloid leukemia, lymphoid or plasma cell malignancies, and in transfusion or transplants field. Using this principle, some drugs, such as: amiloride, lovastatin and pravastatin, can also be detected ${ }^{43}$.

\section{CONCLUSIONS}

The activity of NHE-1 increases during malignant cell transformation and correlates with a reversed proton gradient (a rise of intracellular $\mathrm{pH}$ and a decrease of extracellular $\mathrm{pH}$ of tumor environment). Thus, cancer cell can avoid apoptosis. This exchanger can also be activated by a wide range of factors.

Hypoxia could inhibit the activity of NHE-1, a fact involved in the mediation of K562 cells differentiation by the pathway of extracellular signal-regulated protein kinases $1 \frac{1}{2}$. Cariporide synergistically enhanced K562 cells differentiation in a hypoxic environment.

Some statins, such as lovastatin, are involved in intracellular acidification due to a partial inhibition of NHE.

During treatment with sorafenib of patients with acute myeloid leukemia with FLT3-ITD mutation a secondary tyrosine kinase domain mutation can appear and an upregulation of gene encoding tescalcin which activates NHE-1. Convincing studies with NHE-1 inhibitors are needed to demonstrate their practical effectiveness in the treatment of these patients.

NHE-1 inhibitors are able to increase the sensitivity of chronic myeloid leukemia cells to tyrosine kinase inhibitors - a finding that could be extremely useful for the treatment of patients with chronic myeloid leukemia resistant to tyrosine kinase inhibitors. They also seem to act by the inhibition of P-glycoprotein.

Future studies are needed to clarify the role that NHE1 inhibitors can play in the treatment of solid and hematological malignancies. Until then, they are an attractive and promising field of research, rediscovered after finding the existence of NHE-1 overexpression in patients treated with sorafenib for acute myeloid leukemia with FLT3/ ITD mutation and in chronic myeloid leukemia resistant to imatinib.

The combination of NHE-1 inhibitors with monoclonal antibodies to increase their arrival to the targeted cell, or with different tyrosine kinase inhibitors or other drugs to increase their efficacy are subjects of study for the future oncohematological practice.

Nevertheless, the involvement of NHE-1 in the mechanisms of cell differentiation and dedifferentiation is far 
from clear, and it could offer beneficial surprises in understanding the process of malignant transformation and can change the approach to cancer and its treatment.

\section{ABBREVIATIONS}

CHOP1, CCAAT/enhancer binding protein homologous protein; DMA, 5'-(N,N-dimethyl)-amiloride; EIPA, 5-N-ethyl-N-isopropyl amiloride; ERK1/2, extracellular signal-regulated protein kinases $1 / 2$; FLT3-ITD, fms-like tyrosine kinase 3; HMA, 5-(N, N-hexamethylene)-amiloride; $\mathrm{NHE}, \mathrm{Na}^{+} / \mathrm{H}^{+}$exchanger; NHE-1, $\mathrm{Na}^{+} / \mathrm{H}^{+}$exchanger- 1 ; p38 MAPK, p38-mitogen-activated protein kinase; PKC, Protein kinase $\mathrm{C}$; TESC, gene encoding tescalcin.

Conflict of interest statement: The author states that there are no conflicts of interest regarding the publication of this article.

\section{REFERENCES}

1. Hrgovic I, Glavic Z, Kovacic Z, Mulic S, Zunic L, Hrgovic Z. Repeated administration of inhibitors for ion pumps reduce markedly tumor growth in vivo. Med Arch 2014;68(2):76-8.

2. Spugnini EP, Sonveaux P, Stock C, Perez-Sayans M, De Milito A, Avnet S, Garcìa AG, Harguindey S, Fais S. Proton channels and exchangers in cancer. Biochim Biophys Acta 2014;1848(10 Pt B):2715-26.

3. Daniel C, Bell C, Burton C, Harguindey S, Reshkin SJ, Rauch C. The role of proton dynamics in the development and maintenance of multidrug resistance in cancer. Biochim Biophys Acta 2013;1832(5):60617.

4. Rich IN, Worthington-White D, Garden OA, Musk P. Apoptosis of leukemic cells accompanies reduction in intracellular $\mathrm{pH}$ after targeted inhibition of the $\mathrm{Na}(+) / \mathrm{H}(+)$ exchanger. Blood 2000;95(4):1427-34.

5. Malo ME, Fliegel L. Physiological role and regulation of the $\mathrm{Na}^{+} / \mathrm{H}^{+}$ exchanger. Can J Physiol Pharmacol 2006 Nov;84(11):1081-95.

6. Reshkin SJ, Cardone RA, Harguindey S. $\mathrm{Na}^{+}-\mathrm{H}^{+}$exchanger, $\mathrm{pH}$ regulation and cancer. Recent Pat Anticancer Drug Discov 2013;8(1):85-99.

7. Harguindey S, Arranz JL, Polo Orozco JD, Rauch C, Fais S, Cardone RA, Reshkin SJ. Cariporide and other new and powerful NHE1 inhibitors as potentially selective anticancer drugs--an integral molecular/ biochemical/metabolic/clinical approach after one hundred years of cancer research. J Transl Med 2013;11:282

8. Reshkin SJ, Bellizzi A, Caldeira S, Albarani V, Malanchi I, Poignee M, Alunni-Fabbroni M, Casavola V, Tommasino M. Na+/H+ exchangerdependent intracellular alkalinization is an early event in malignant transformation and plays an essential role in the development of subsequent transformation-associated phenotypes. FASEB 2000;14(14):2185-97.

9. Mirossay A, Mirossay L, Sarisský M, Papp P, Mojzis J. Modulation of the phototoxic effect of hypericin in human leukemia CEM cell line by $\mathrm{N}$-ethylmaleimide, amiloride and omeprazole. Physiol Res 2002;51(6):641-4.

10. Mirossay L, Mirossay A, Kocisová E, Radváková l, Miskovský P, Mojzis J. Hypericin-induced phototoxicity of human leukemic cell line $\mathrm{HL}-60$ is potentiated by omeprazole, an inhibitor of $\mathrm{H}^{+} \mathrm{K}^{+}$-ATPase and $5^{-}$-(N,N-dimethyl)-amiloride, an inhibitor of $\mathrm{Na}^{+} / \mathrm{H}^{+}$exchanger. Physiol Res 1999;48(2):135-41.

11. Man CH, Lam SS, Sun MK, Chow HC, Gill H, Kwong YL, Leung AY. A novel tescalcin-sodium/hydrogen exchange axis underlying sorafenib resistance in FLT3-ITD+ AML. Blood 2014;123(16):2530-9.

12. Jin W, Li Q, Lin Y, Lu Y, Li H, Wang L, Hu R, Ma L, Wang J, Pang T. Reversal of Imatinib resistance in $B C R$ - $A B L$-positive leukemia after inhibition of the $\mathrm{Na}+/ \mathrm{H}+$ exchanger. Cancer Lett 2011;308(1):81-90.

13. Affar el B, Shah RG, Dallaire AK, Castonguay V, Shah GM. Role of poly(ADP-ribose) polymerase in rapid intracellular acidification induced by alkylating DNA damage. Proc Natl Acad Sci U S A 2002;99(1):245-50.

14. Wang J, Xu H, Zhang $\mathrm{H}$, Wang $\mathrm{Q}$, Wang $\mathrm{C}$, Zhang $\mathrm{H}$, Lin $\mathrm{Y}$, Ru Y, Liang $\mathrm{H}$, Li Q1, Pang T. CIAPIN1 targets $\mathrm{Na}^{+} / \mathrm{H}^{+}$exchanger 1 to mediate K562 chronic myeloid leukemia cells' differentiation via ERK1/2 signaling pathway. Leuk Res 2014;38(9):1117-25.

15. Mebratu Y, Tesfaigzi Y. How ERK1/2 activation controls cell proliferation and cell death: Is subcellular localization the answer? Cell Cycle 2009;8(8):1168-75.

16. Shin S, Dimitri CA, Yoon SO, Dowdle W, Blenis J. ERK2, but not ERK1, induces epithelial to mesenchymal transformation via DEF motif dependent signaling events. Mol Cell 2010;38(1):114-27.

17. Garden OA, Musk P, Worthington-White DA, Dewey MJ, Rich IN. Silent polymorphisms within the coding region of human sodium/hydrogen exchanger isoform-1 cDNA in peripheral blood mononuclear cells of leukemia patients: A comparison with healthy controls. Cancer Genet Cytogenet 2000;120(1):37-43.

18. Hallows KR, Restrepo D, Knauf PA. Control of intracellular pH during regulatory volume decrease in HL-60 cells. Am J Physiol 1994;267(4 Pt 1):C1057-66.

19. Jin W, Li Q, Wang J, Chang G, Lin Y, Li H, Wang L, Gao W, Pang T. Na+/ $\mathrm{H}+$ exchanger 1 inhibition contributes to K562 leukaemic cell differentiation. Cell Biol Int 2012;36(8):739-45.

20. Jin WN, Wang J, Chang GQ, Lin YN, Wang LH, Li HW, Gao W, Li QH, Pang TX. Inhibition of NHE1 promotes hypoxia-induced differentiation of K562 leukemic cells. Zhongguo Shi Yan Xue Ye Xue Za Zhi 2011;19(3):661-5.

21. Zhao R, Oxley D, Smith TS, Follows GA, Green AR, Alexander DR. DNA damage-induced $\mathrm{BCl}-\mathrm{xL}$ deamidation is mediated by $\mathrm{NHE}-1$ antiport regulated intracellular $\mathrm{pH}$. PLoS Biol 2007;5(1):e1.

22. Zhao R, Follows GA, Beer PA, Scott LM, Huntly BJ, Green AR, Alexander DR. Inhibition of the $\mathrm{Bcl}-\mathrm{xL}$ deamidation pathway in myeloproliferative disorders. Engl J Med 2008;359(26):2778-89.

23. Rich IN, Worthington-White D, Garden OA, Musk P. Apoptosis of leukemic cells accompanies reduction in intracellular $\mathrm{pH}$ after targeted inhibition of the $\mathrm{Na}^{(+)} / \mathrm{H}^{(+)}$exchanger. Blood 2000;95(4):1427-34.

24. Masereel B, Pochet L, Laeckmann D. An overview of inhibitors of $\mathrm{Na}^{(+)} / \mathrm{H}^{(+)}$exchanger. European Journal of Medicinal Chemistry 2003;38(6):547-54.

25. Chang WH, Liu TC, Yang WK, Lee CC, Lin YH, Chen TY, Chang JG. Amiloride modulates alternative splicing in leukemic cells and resensitizes Bcr-AblT315I mutant cells to imatinib. Cancer Res 2011;71(2):383-92.

26. Gao W, Zhang H, Chang G, Xie Z, Wang H, Ma L, Han Z, Li Q, Pang $\mathrm{T}$. Decreased intracellular $\mathrm{pH}$ induced by cariporide differentially contributes to human umbilical cord-derived mesenchymal stem cells differentiation. Cell Physiol Biochem 2014;33(1):185-94.

27. Li H, Chang G, Wang J, Wang L, Jin W, Lin Y, Yan Y, Wang R, Gao W, Ma L, Li Q, Pang T. Cariporide sensitizes leukemic cells to tumor necrosis factor related apoptosis-inducing ligand by up-regulation of death receptor 5 via endoplasmic reticulum stress-CCAAT/enhancer binding protein homologous protein dependent mechanism. Leuk Lymphoma 2014;55(9):2135-40.

28. Gao W, Chang G, Wang J, Jin W, Wang L, Lin Y, Li H, Ma L, Li Q, Pang T. Inhibition of K562 leukemia angiogenesis and growth by selective $\mathrm{Na}^{+} / \mathrm{H}^{+}$exchanger inhibitor cariporide through down-regulation of pro-angiogenesis factor VEGF. Leuk Res 2011;35(11):1506-11.

29. Pérez-Sala D, Collado-Escobar D, Mollinedo F. Intracellular alkalinization suppresses lovastatin-induced apoptosis in HL-60 cells through the inactivation of a $\mathrm{pH}$-dependent endonuclease. J Biol Chem 1995;270(11):6235-42.

30. Clark SS, Perman SM, Sahin MB, Jenkins GJ, Elegbede JA. Antileukemia activity of perillyl alcohol $(\mathrm{POH})$ : uncoupling apoptosis from G0/G1 arrest suggests that the primary effect of $\mathrm{POH}$ on $\mathrm{Bcr} / \mathrm{Abl}$-transformed cells is to induce growth arrest. Leukemia 2002;16(2):213-22.

31. Alvarado Y, Kantarjian HM, Luthra R, Ravandi F, Borthakur G, GarciaManero G, Konopleva M, Estrov Z, Andreeff M, Cortes JE. Treatment with FLT3 inhibitor in patients with FLT3-mutated acute myeloid leukemia is associated with development of secondary FLT3-tyrosine kinase domain mutations. Cancer 2014;120(14):2142-9.

32. Ma D, Fang Q, Wang P, Gao R, Wu W, Lu T, Cao L, Hu X, Wang J. Induction of heme oxygenase- 1 by $\mathrm{Na}^{+}-\mathrm{H}^{+}$exchanger 1 protein plays 
a crucial role in imatinib-resistant chronic myeloid leukemia cells. Biol Chem 2015;290(20):12558-71.

33. Hu RH, Jin WN, Chang GQ, Lin YN, Wang J, Ru YX, Li QH, Pang TX. Increasing sensitivity of leukemia cells to imatinib by inhibiting NHE1 and p38MAPK signaling pathway. Zhongguo Shi Yan Xue Ye Xue Za Zhi 2012;20(6):1341-5.

34. Li QH, Lu Y, Jin WN, Lin YN, Hu RH, Zhu XF, Wang JX, Pang TX. Effect of intracellular acidification on drug resistance of leukemia cells with high P-glycoprotein expression. Zhonghua Xue Ye Xue Za Zhi 2009;30(9):605-9.

35. Sih HJ, Stolen C, Ou J, Wagner DO. Methods to position therapeutic agents using a magnetic field. US 20080006281 (2008).

36. Wishart N, Argiriadi MA, Calderwood DJ, Ericsson AM, Fiamengo BA Frank KE, Friedman MM, George DM, Goedken ER, Josephsohn NS, Li BC, Stewart KD, Wallace GA, Wang L, Woller KR. Tricyclic compounds. US 20090312338 (2009).
37. Wishart N, Frank KE, Friedman M, George DM, Stewart KD, Wallace GA. Tricyclic compounds. US 20110311474 (2011).

38. Watterson DM, Van Eldik LJ. Protein kinase targeted therapeutics. US 20110166153 (2011).

39. Ghayur T, Salfeld JG, McPherson MJ. Dual variable domain immunoglobulins and uses thereof. US 20120087858 (2012).

40. Rogers RD, Daly DT, Swatloski RP, Hough-Troutman WL, Davis Jr. JH, Smiglak M, Pernak J, Spear SK. Multi-functional ionic liquid compositions for overcoming polymorphism and imparting improved properties for active pharmaceutical, biological, nutritional, and energetic ingredients. US 20120264605 (2012).

41. Wan MM, Avgerinos G, Zarbis-Papastoitsi G. Purified antibody composition. US 20130273059 (2013).

42. Meyer MD, Wang X, Guo T, Wei RGP, Wang LJ. Chemokine receptor antagonists. US 20130261129 (2013).

43. Neely LA, Audeh MJ, Blanco M, Chepin JF, Demas V, Dhanda RK, Lowery Jr. TJ. NMR systems and methods for the rapid detection of analytes. US 20130266944 (2013). 